\title{
Early morbidity and dose-volume effects in definitive radiochemotherapy for locally advanced cervical cancer: a prospective cohort study covering modern treatment techniques
}

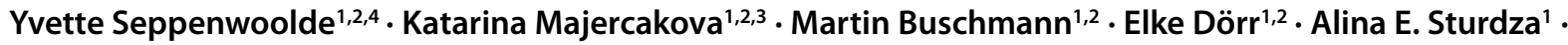 \\ Maximilian P. Schmid ${ }^{1} \cdot$ Richard Pötter $^{1,2} \cdot$ Dietmar Georg $^{1,2}$
}

Received: 13 October 2020 / Accepted: 30 March 2021 / Published online: 30 April 2021

(c) The Author(s) 2021

\begin{abstract}
Purpose Predicting morbidity for patients with locally advanced cervix cancer after external beam radiotherapy (EBRT) based on dose-volume parameters remains an unresolved issue in definitive radiochemotherapy. The aim of this prospective study was to correlate patient characteristics and dose-volume parameters to various early morbidity endpoints for different EBRT techniques, including volumetric modulated arc therapy (VMAT) and adaptive radiotherapy (ART).

Methods and materials The study population consisted of 48 patients diagnosed with locally advanced cervix cancer, treated with definitive radiochemotherapy including image-guided adaptive brachytherapy (IGABT). Multiple questionnaires (CTCAE 4.03, QLQ-C30 and EORTC QLQ-CX24) were assessed prospectively for patients treated with different EBRT techniques, including online adaptive VMAT. Contouring and treatment planning was based on the EMBRACE protocols. Acute toxicity, classified as general, gastrointestinal (GI) or genitourinary (GU) and their corresponding dose-volume histograms (DVHs) were first correlated by applying least absolute shrinkage and selection operator (LASSO) and subsequently evaluated by multiple logistic binomial regression.

Results The treated EBRT volumes varied for the different techniques with $\sim 2500 \mathrm{~cm}^{3}$ for $3 \mathrm{D}$ conformal radiotherapy (3D-CRT), $\sim 2000 \mathrm{~cm}^{3}$ for EMBRACE-I VMAT, and $\sim 1800 \mathrm{~cm}^{3}$ for EMBRACE-II VMAT and ART. In general, a worsening of symptoms during the first 5 treatment weeks and recovery afterwards was observed. Dose-volume parameters significantly correlating with stool urgency, rectal and urinary incontinence were as follows: bowel $\mathrm{V}_{40 \mathrm{~Gy}}<250 \mathrm{~cm}^{3}$, rectum $\mathrm{V}_{40 \mathrm{~Gy}}<80 \%$ and bladder $\mathrm{V}_{40 \mathrm{~Gy}}<80-90 \%$.

Conclusion This prospective study demonstrated the impact of EBRT treatment techniques in combination with chemotherapy on early morbidity. Dose-volume effects for dysuria, urinary incontinence, stool urgency, diarrhea, rectal bleeding, rectal incontinence and weight loss were found.
\end{abstract}

Keywords Image-guided adaptive radiotherapy $\cdot$ Radiotherapy $\cdot$ Brachytherapy $\cdot$ Organs-at-risk toxicity $\cdot$ Quality of life

Dietmar Georg

dietmar.georg@meduniwien.ac.at

1 Department of Radiation Oncology, Comprehensive Cancer Center, Medical University of Vienna/AKH Wien, Währinger Gürtel 18-20, 1090 Vienna, Austria

2 Christian Doppler Laboratory for Medical Radiation Research for Radiation Oncology, Medical University of Vienna, Vienna, Austria

3 Department of Radiation Oncology, Hospital de la Santa Creu i Sant Pau, Barcelona, Spain

4 Department of Radiation Oncology, Erasmus MC Cancer Institute, Rotterdam, The Netherlands

\section{Introduction}

Radiation oncology plays a major role in the treatment of locally advanced cervical cancer. Current standard of care is concurrent radiochemotherapy combining external beam radiotherapy (EBRT) with cisplatin followed by a brachytherapy (BT) boost, preferably by image-guided adaptive brachytherapy (IGABT; [1]).

Advanced EBRT techniques, especially those based on intensity modulation, enabled improved organ-at-risk (OAR) sparing and consequently decreased the incidence of severe toxicity (G3, G4) [2, 3]. Intensity modulated radiotherapy (IMRT) and volumetric modulated arc therapy 
(VMAT) with small margins are challenging in cervical cancer, because of large intra- and interfraction motion [4-7]. Therefore, adaptive radiotherapy (ART) that adjusts treatment plans according to organ movements to further reduce irradiated volumes has become a main research interest [8-15].

Despite these advancements, 60-70\% of patients still experience early lower grade (G1-2) side effects, of which $30 \%$ develop into late morbidity $[16,17]$. Several publications concluded that especially gastrointestinal (GI), genitourinary (GU) and vaginal/sexual problems have an impact on quality of life (QoL) [8, 18, 19]. Furthermore, observational studies demonstrated that radiochemotherapy leads to more physical, psychological and sexual sequelae [18, 20-22], especially in premenopausal patients. However, none of those studies correlated side effects with dose distributions.

Unraveling the EBRT effects from brachytherapy and chemotherapy effects is challenging. At the time of BT, the full EBRT dose might not have yet been delivered and is mostly in the lower range of the tolerance dose $\left(\mathrm{TD}_{50}\right)$ for rectum and bladder [23]. On the contrary, and based on the authors' experience, the recommended dose-volume parameter for small bowel $\left(\mathrm{V}_{45 \mathrm{~Gy}}<195 \mathrm{~cm}^{3}\right)$ is exceeded for most cervix patients. For small bowel tolerance, no difference in the incidence of small bowel toxicity was found for doses from 5 to 40Gy [24], while another study concluded that $\mathrm{V}_{16 \mathrm{~Gy}}$ should be $<290 \mathrm{~cm}^{3}$ for patients without prior abdominal surgery to prevent $>\mathrm{G} 2$ acute diarrhea [25]. For bladder, grade 3 late toxicity was found to occur for doses $>50 \mathrm{~Gy}$ [26] and the $\mathrm{TD}_{50}$ of patient reported symptoms is often $>85 \mathrm{~Gy}$ [27]. Late rectal injury was found to be rare in current dose ranges [28].

The aim of this mono-institutional observational study was to assess early morbidity as a function of EBRT dose distributions for different techniques, varying from 3D-CRT to VMAT-ART, the latter being based on a bladder filling/ uterus motion model. Early side effects were assessed using multiple questionnaires (patient and physician reported). Dose-volume parameters as well as patient demographics were correlated with early morbidity at different time points with the aim to determine dose-effect relations and predictive factors.

\section{Materials and methods}

\section{Patient cohorts and treatment}

The inclusion criteria were: age $\geq 18$ years, histologically proven locally advanced cervix cancer FIGO Ib-IVb (para-aortic lymph node metastasis), no previous radio- or chemotherapy, patients suitable for definitive treatment, no other diagnosis of tumor and patients capable to treatment and study compliance.

All 48 included patients were treated with definitive radiochemotherapy including consecutive MRI-guided IGABT. A total of 44 patients $(92 \%)$ received chemotherapy. Patient-specific parameters (PsP) like smoking, alcohol, chemotherapy (both regimen and the number of completed cycles), the use of para-aortic nodal fields (PAN) and age were collected as well. The patients' characteristics of this ethics-committee-approved study are summarized in Fig. 1.

Target and organ-at-risk (OAR) delineation as well as treatment planning were based either on EMBRACE-I and later EMBRACE-II guidelines [29], though not all patients were participating in those studies. The bowel bag was recontoured as in EMBRACE-II guidelines. EBRT was administered with a total dose of $45 \mathrm{~Gy} / 1.8 \mathrm{~Gy}$ per fraction. After the introduction of VMAT, a 55-60 Gy simultaneous boost (SIB, 2.2-2.4 Gy per fraction) was given to positive pelvic or para-aortal lymph nodes. EBRT was followed by IGABT in 4 fractions with 2 applications, with the planning aim to achieve a $\mathrm{D}_{90 \%}$ of $85 \mathrm{~Gy}\left(\mathrm{EQD}_{2}\right)$ for the $\mathrm{CTV}_{\mathrm{HR}}$.

The EBRT technique was not explicitly predefined for this study to allow for a progression of treatment technology over time. EBRT treatment evolved over time from 3DCRT, via single plan VMAT to an ART protocol based on a library approach (plan of the day= PotD), encompassing VMAT plans for empty and full bladder plus a motion robust VMAT plan. Daily CBCT information was utilized to select the most suitable library plan [15]. A drinking protocol with the aim of comfortably full-bladder was routinely used in all groups. An empty rectum was advised, but no specific rectum protocol was provided.

\section{Acute toxicity scoring}

Acute toxicity was evaluated by Common Terminology Criteria for Adverse Events (CTCAE) 4.03 (physicianreported; PhysRO) [30] complemented by local reporting items (daily micturition, stool consistency and stool urgency) and patient-reported (PRO) Quality of Life Questionnaire (QLQ)-C30 and EORTC QLQ-CX24 questionnaires. The evaluation was performed before treatment, weekly during treatment, and 1, 6 and 12 weeks after finishing EBRT. The patients evaluated the grade of the symptoms as none, a little, quite a bit and very much. For each PhysRO question, corresponding PRO questions were determined and analyzed.

The evaluation of stool consistency was based on Bristol stool form scale, assessing the stool type from 1-7, where 1-3 means constipation (scored separately), 4-5 normal, 6 mushy and 7 liquid stool [31]. Urine frequency 5-7 times a day was considered normal. For daily micturition the fol- 
Fig. 1 Distribution of patients over the FIGO stages, number of completed chemotherapy cycles, simultaneous integrated boost (SIB), extended fields (PAN) and irradiation technique. Embrace$I / / I I$ patients were delineated and planned according to the respective study protocols, but not all were included in those studies. PotD plan of the day, $3 D C R T 3 D$ conformal radiotherapy
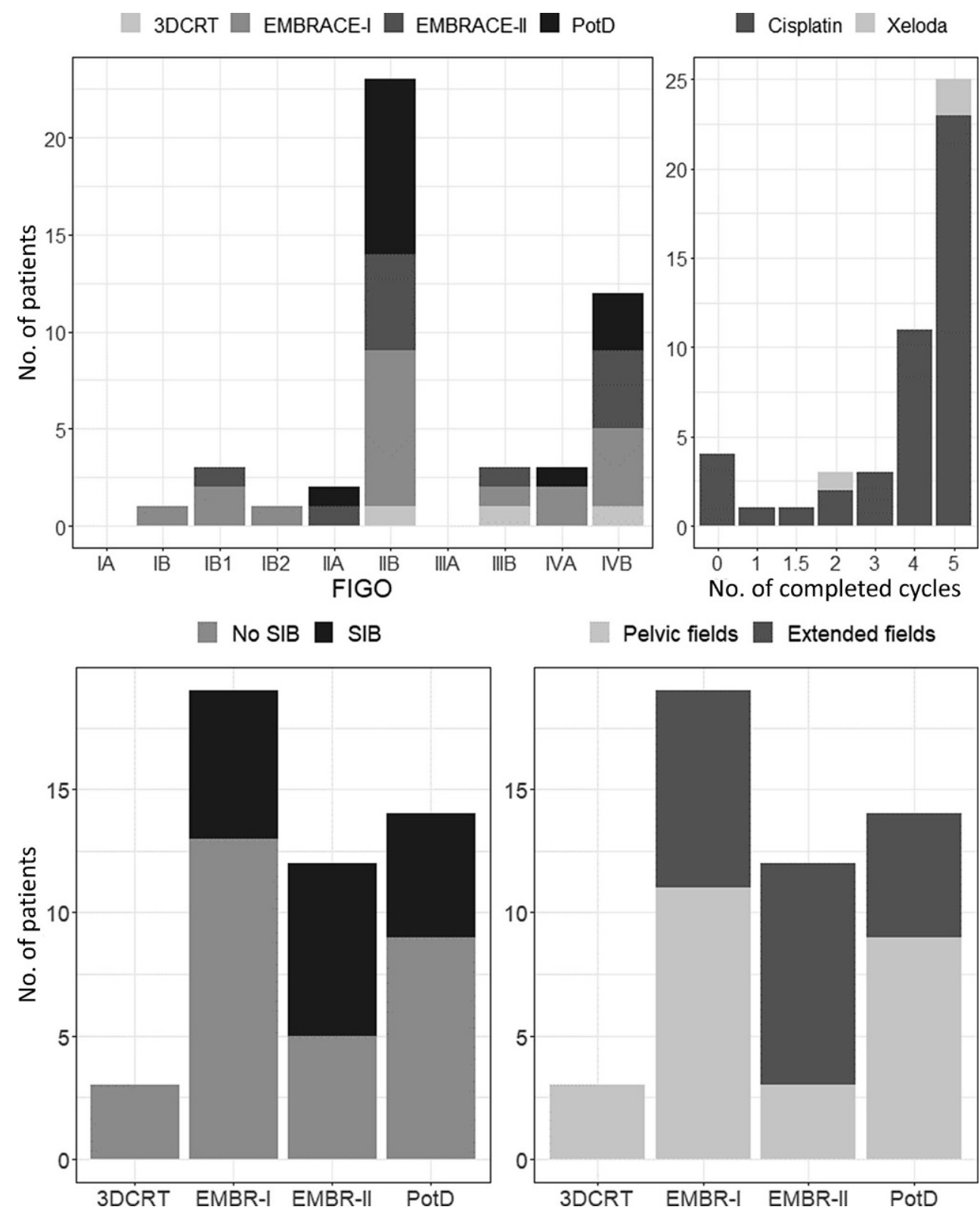

lowing groups were introduced: $<5,6-7,8-14,>14$ times a day. Synchronous to the introduction of VMAT, extra patient-related questions were added (QLQ 55-59) to provide more detailed information. The questions were grouped into general, GI and GU toxicity and were analyzed accordingly.

\section{Dose-volume parameters}

The following dose-volume (DV) parameters were derived from all EBRT plans: Sigmoid $\mathrm{V}_{40 \mathrm{~Gy}}$, Rectum $\mathrm{V}_{40 \mathrm{~Gy}}$ and $\mathrm{V}_{\text {30Gy }}$, Bladder $\mathrm{V}_{40 \mathrm{~Gy}}$ and $\mathrm{V}_{30 \mathrm{~Gy}}(\%)$, Bowel $\mathrm{V}_{40 \mathrm{~Gy}}$ and $\mathrm{V}_{\text {30Gy }}$ (cc), Body $\mathrm{V}_{43 \mathrm{~Gy}}(\mathrm{cc})$. For all ART patients, the DV parameters for each of the three VMAT plans were weighted with the frequencies of their use in the clinic, resulting in one average weighted overall value.

\section{Time series}

At all analyzed time points, reported side effects were corrected for their corresponding baseline values in order to avoid bias from pre-existing complaints or of symptoms that may be due to the disease itself. While the maximum EBRT dose before the start of BT can be linked with the 5 week time point, the chemotherapy (CHT) influence (e.g., nausea and diarrhea) was difficult to separate. Although almost all patients received similar chemotherapy regimens, the following PsP classification for CHT regimen was evaluated: 
$0=$ no chemotherapy, $0.5=$ capecitabine, $1=$ cisplatin. An additional factor with the number of completed chemotherapy cycles was included as well.

\section{Statistics}

All statistical calculations were performed utilizing $\mathrm{R}$ (www.R-project.org) [32, 33]. In case multiple parameters correlated with an effect, e.g., bladder $\mathrm{V}_{30 \mathrm{~Gy}}$ and $\mathrm{V}_{40 \mathrm{~Gy}}$, only the most significant univariate parameter was selected beforehand. We only selected specific parameters that seemed to be logical into the analyses. Patients with missing values for one of the side effects were excluded from the analysis only if that specific effect was under evaluation.

For relevant feature selection of DV and PsP, LASSO was used [34]. LASSO (least absolute shrinkage and selection operator) is a regression analysis method that performs both variable selection and regularization in order to enhance the prediction accuracy and interpretability of the statistical model it produces. As the number of incidences was sparse, especially in the more severe categories, higher scores were added to the lower category because glmnets' LASSO works best for binomial parameters (glmnet is an $\mathrm{R}$ package that fits a generalized linear model via penalized maximum likelihood).

For the final parameters selected by LASSO, multiple logistic binomial regression was performed with only the selected parameters to maximize the information and to minimize the effect of missing values. In case a clear threshold dose was present, a Fisher's exact test was performed. The significance of DV and PsP for the continuous variable weight loss was determined by multivariate stepwise regression at two timepoints: just before the start of BT and at the end of treatment.

\section{Results}

From October 2014 until February 2018, 48 patients with median age of 54 (range 31-74) and FIGO stage Ib-IVb, were included in the analysis of early side effects (Fig. 1). Almost all patients received concomitant weekly cisplatin $40 \mathrm{mg} / \mathrm{m}^{2}, 3$ patients received capecitabine (Xeloda, Genentech Inc, South San Francisco, CA, USA) and four patients did not receive chemotherapy because of renal insufficiency. The number of completed cycles is shown in Fig. 1. In all, 22 patients smoked, 7 had quit and 17 patients were nonsmokers.

Three patients received 3D-CRT, 31 patients were treated with VMAT with fixed margins based on a single CT scan and 14 patients with large uterus motion received ART. A total of 18 patients received SIB-VMAT plan and 22 received extended field irradiation (with VMAT).

At the 3-month follow-up (FU), 43 patients had complete remission, 1 patient incomplete remission, 2 patients had distant systemic progressive disease and 2 patients were lost to long-term follow-up. During further FU beyond this study (median 16 months), 2 patients developed local failure, 1 pelvic nodal failure, 2 para-aortic nodal failures and 10 patients developed distant metastases beyond para-aortic lymph nodes.
Fig. 2 Boxplots of volumes irradiated to at least $43 \mathrm{~Gy}$ (V43Gy) in cc for the different irradiation techniques (EBRT treatment evolved over time from 3D conformal radiotherapy (3DCRT), via single plan VMAT (based on EMBRACE I and later EMBRACE II guidelines) to an ART protocol based on a library approach (plan of the day $=$ PotD)). The Robust equivalent is provided as a reference for the larger volume the PotD patients would have been irradiated to, in case they would not have been adapted every fraction

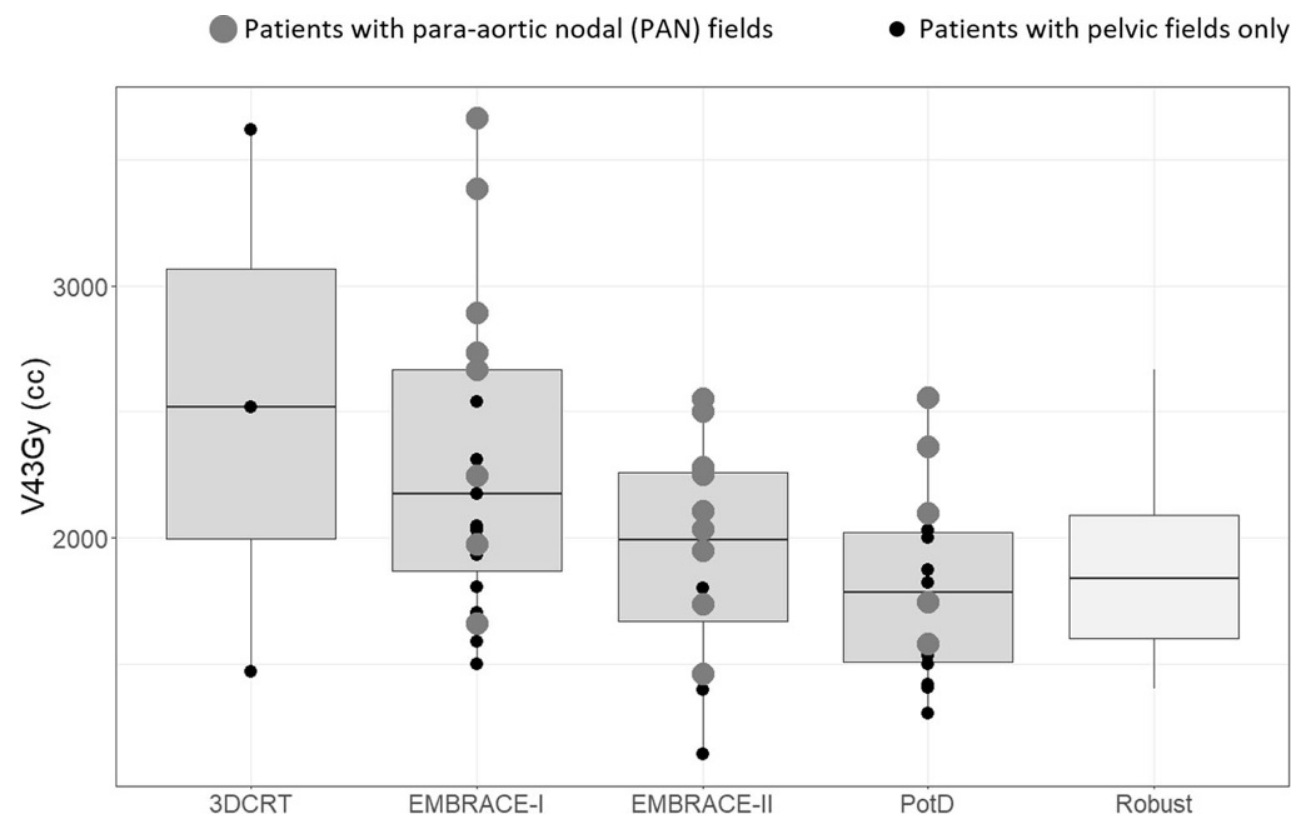


Fig. 3 Distribution of dose-volume parameters. PotD plan of the day. 3DCRT 3D conformal radiotherapy
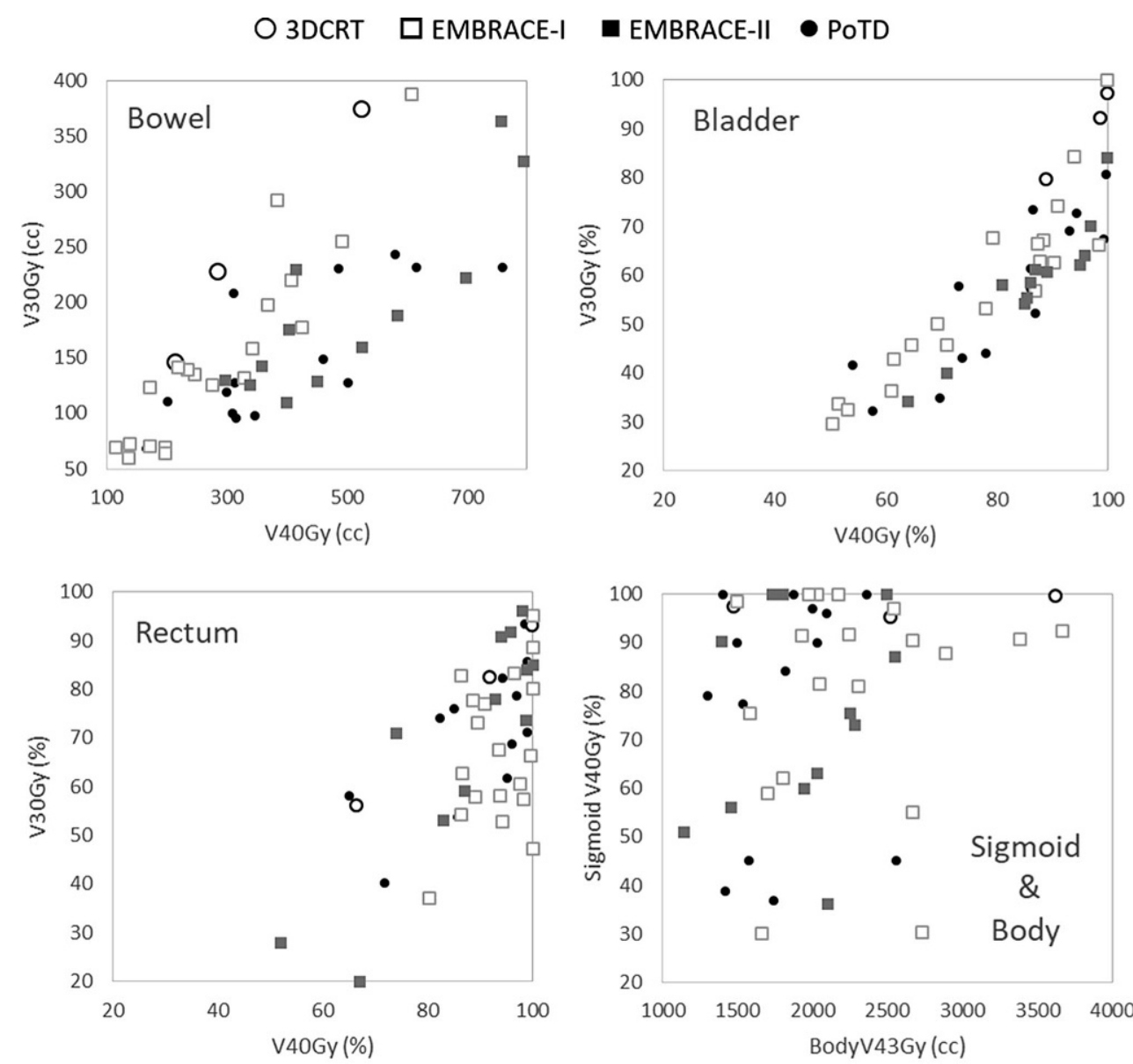

\section{Irradiated EBRT volumes}

As shown in Fig. 2, the volumes exposed to $43 \mathrm{~Gy}$ (95\% of prescribed dose) varied for the different EBRT techniques. $\mathrm{V}_{43 \mathrm{~Gy}}$ was largest for the few patients receiving 3D-CRT $\left(\sim 2500 \mathrm{~cm}^{3}\right)$, somewhat lower for patients enrolled in the EMBRACE I study $\left(\sim 2000 \mathrm{~cm}^{3}\right)$ treated with VMAT, and lowest for patients planned according to EMBRACE II, treated with either VMAT or ART $\left(\sim 1800 \mathrm{~cm}^{3}\right)$. In general the V43Gy for extended (PAN) fields was larger: $\sim 2250 \mathrm{~cm}^{3}$ vs $\sim 1600 \mathrm{~cm}^{3}$ over the entire patient group. However, for the recent techniques, the volume of the extended fields were often smaller than the small fields of the older techniques.

In only $8 \%$ of ART treatment sessions, the (larger) robust plan was chosen, while $35 \%$ of the delivered ART fractions were based on the full bladder plan and $57 \%$ for the empty bladder plan. In other words, in $92 \%$ of all ART fractions $\mathrm{V}_{43 \mathrm{G} y}$ was smaller than it would have been otherwise.

Differences between EBRT treatment techniques and the underlying target definition protocol (EMBRACE I vs II) were larger and more significant for the higher dose-volume parameters. The volume differences between ART and EMBRACE II patients were often due to target volume variations (nodal SIB, pelvic and para-aortal lymph nodes (PLN)). In Fig. 3, the range and distribution of the various dose-volume parameters is depicted.

Table 1 summarizes the analysis of the DV parameters for primary OAR. On average, ART reduced the irradiated normal tissue volumes to $43 \mathrm{~Gy}$ by $80 \mathrm{~cm}^{3}$. More specifically, bowel tissue irradiated to $\geq 40 \mathrm{~Gy}$ was reduced by $17 \mathrm{~cm}^{3}$ and bladder volume irradiated receiving $\geq 40 \mathrm{~Gy}$ by $5 \%$, respectively.

\section{Patient and physician reported side effects}

The PRO evaluation was found to be more sensitive in terms of both incidence and grading of toxicity for all side effects, but most prominent for dysuria (see Appendix). Table 2 and Fig. 4 provide an overview of the side effects that were found to correlate with one or more DV parameters. In general, a worsening of symptoms during the first 5 weeks of treatment and recovery afterwards was observed. No G4-G5 toxicity was reported. 
Table 1 Differences and significance of dose-volume parameters for the plan of the day patients compared to their robust plan

\begin{tabular}{lll}
\hline & Average Difference & $p$-value (paired t-test) \\
\hline Sigmoid $\mathrm{V}_{40 \mathrm{~Gy}}$ & $-3 \%$ & 0.08 \\
Bowel $\mathrm{V}_{30 \mathrm{~Gy}}$ & $-13 \mathrm{cc}$ & 0.2 \\
Bowel $_{40 \mathrm{~Gy}}$ & $-17 \mathrm{cc}$ & $\mathbf{0 . 0 0 7}$ \\
Rectum $\mathrm{V}_{30 \mathrm{~Gy}}$ & $0 \%$ & 0.7 \\
Rectum $\mathrm{V}_{40 \mathrm{~Gy}}$ & $-2 \%$ & 0.08 \\
Bladder $\mathrm{V}_{\text {30Gy }}$ & $-6 \%$ & 0.2 \\
Bladder $\mathrm{V}_{40 \mathrm{~Gy}}$ & $-5 \%$ & 0.1 \\
Body $\mathrm{V}_{43 \mathrm{~Gy}}$ & $-80 \mathrm{cc}$ & $\mathbf{0 . 0 0 0 1}$ \\
\hline
\end{tabular}

\section{Acute gastrointestinal side effects}

From all gastrointestinal (GI) collected symptoms (nausea, vomiting, stool consistency, diarrhea, constipation, bloating, flatulence, stool urgency, rectal tenesmus, rectal mucus, rectal bleeding, rectal incontinence and proctitis) only stool consistency, diarrhea, stool urgency, rectal bleeding and rectal incontinence revealed dose effects in the multivariate logistic regression analysis. Stool consistency was found to be influenced by age, CHT and smoking (Table 2). The majority of patients developed diarrhea already in the first weeks of treatment, which indicates an early RT effect combined with CHT and smoking with the accumulated received dose being still small. During the treatment a slight recovery was observed (for the dynamics of side effects over time, see
Appendix). Only for the patients who showed persistent diarrhea in the follow-up just after treatment was a dose effect of the Bowel parameter $\mathrm{V}_{30 \mathrm{~Gy}}$ obtained, regardless of BT. $\mathrm{CHT}$ also played a role in stool urgency. Almost full recovery was present in the longer follow-up, as for the other parameters. The significant dose-volume parameter for stool urgency was the Bowel $\mathrm{V}_{40 \mathrm{~Gy}}$, with a $\mathrm{V}_{40 \mathrm{~Gy}} \sim 250 \mathrm{~cm}^{3}$. For rectal incontinence, a shallow dose-effect relation was observed, with very low incidence even at higher irradiated volumes; a Rectum $\mathrm{V}_{40 \mathrm{~Gy}}$ above $80 \%$ increased the (sparse) incidence significantly in combination with CHT. Rectal bleeding seemed to be an EBRT effect as this side effect increased in week 4-5 (4 patients, 8\%) and recovered quickly after treatment (6-week and 3-month followup) without showing worsening after brachytherapy. Rectal bleeding was absent for Rectum $\mathrm{V}_{30 \mathrm{~Gy}}<96 \%$, and increased to $20 \%$ for $\mathrm{V}_{30 \mathrm{~Gy}}$ above $96 \%$. Due to the low total number of incidences, this was borderline significant (Fisher's exact test: $p$-value $=0.054$ ).

\section{Acute genitourinary side effects}

From all collected genitourinary (GU) side effects (see Appendix A), only dysuria with its highest incidence in week 5 (18 patients, 38\%) and bladder incontinence at the time points week 6 and 1 week after treatment completion (14 patients, 29\%) remained significant in the multivariate logistic regression. Both symptoms were influenced by

Table 2 Overview of dose effects that were selected by LASSO are marked with "+" and their (lowest) significance (in numbers) obtained from subsequent multivariate logistic regression analysis

\begin{tabular}{|c|c|c|c|c|c|c|c|c|c|c|c|c|c|}
\hline Side effect & Report & Grade & $\begin{array}{l}\text { Bladder } \\
\text { V40Gy }\end{array}$ & $\begin{array}{l}\text { Rectum } \\
\text { V30Gy }\end{array}$ & $\begin{array}{l}\text { Rectum } \\
\text { V40Gy }\end{array}$ & $\begin{array}{l}\text { Bowel } \\
\text { V40Gy }\end{array}$ & $\begin{array}{l}\text { Body } \\
\text { V43Gy }\end{array}$ & Alcohol & CHT & Smokin & gAge & & $\begin{array}{l}\text { Time } \\
\text { point }\end{array}$ \\
\hline \multirow{2}{*}{$\begin{array}{l}\text { Stool } \\
\text { urgency }\end{array}$} & CTCAE & $\geq 1$ & - & - & + & 0.015 & - & - & - & - & + & - & \multirow[t]{2}{*}{ W5 } \\
\hline & $\mathrm{PRO}^{\mathrm{a}}$ & $\geq 2$ & - & - & - & 0.02 & - & - & - & + & + & - & \\
\hline $\begin{array}{l}\text { Stool con- } \\
\text { sistency }\end{array}$ & - & $\begin{array}{l}\text { Fluid } \\
\text { stool }\end{array}$ & - & 0.009 & - & 0.015 & - & - & - & - & - & - & W5 \\
\hline Diarrhea & PRO & $\geq 1$ & - & - & - & 0.008 & - & - & + & + & - & - & Fu1w \\
\hline \multirow{2}{*}{$\begin{array}{l}\text { Rectal in- } \\
\text { continence }\end{array}$} & CTCAE & \multirow[t]{2}{*}{$\geq 1$} & - & - & 0.006 & + & - & - & + & - & - & - & \multirow[t]{2}{*}{ W6 } \\
\hline & PRO & & - & - & 0.0006 & - & - & - & 0.002 & - & - & - & \\
\hline $\begin{array}{l}\text { Rectal } \\
\text { bleeding }\end{array}$ & $\begin{array}{l}\text { CTCAE } \\
\text { PRO }\end{array}$ & $\geq 1$ & - & 0.05 & - & - & - & - & - & - & - & - & W5 \\
\hline Dysuria & PRO & $\geq 1$ & 0.03 & - & - & - & - & - & + & + & - & - & W6 \\
\hline \multirow{2}{*}{$\begin{array}{l}\text { Bladder in- } \\
\text { continence }\end{array}$} & CTCAE & \multirow[t]{2}{*}{$\geq 1$} & + & - & - & - & - & + & + & 0.0005 & 0.0003 & - & \multirow[t]{2}{*}{ Fu6w } \\
\hline & $\mathrm{PRO}^{\mathrm{a}}$ & & 0.001 & - & - & - & - & + & + & + & 0.003 & - & \\
\hline \multirow[t]{2}{*}{ Weight loss } & \multirow[t]{2}{*}{$\begin{array}{l}\text { Mea- } \\
\text { sured }\end{array}$} & \multirow{2}{*}{$\begin{array}{l}\text { Con- } \\
\text { tinu- } \\
\text { ously }\end{array}$} & - & - & - & - & 0.0007 & 0.01 & - & - & - & - & $\begin{array}{l}\text { Before } \\
\text { brachy }\end{array}$ \\
\hline & & & - & - & - & - & 0.006 & 0.02 & - & - & - & + & $\begin{array}{l}\text { After } \\
\text { brachy }\end{array}$ \\
\hline
\end{tabular}

No significant correlation between number of chemotherapy cycles and any of the general parameters

W5 week 5, W6 week 6, Fulw Follow-up 1 week after finishing of the treatment, Fu6w Follow-up 6 weeks after finishing of the treatment, CHT chemotherapy, PRO patient-reported outcome, CTCAE Common Terminology Criteria for Adverse Events

a Data available only for patients after October 2015

${ }^{\mathrm{b}}$ Sparse data but clear cutoff at RectumV30Gy of $96 \%$ : below: no incidence 
Fig. 4 Dose-volume effect relations for CTCAE gastrointestinal (upper graphs) and patient reported genitourinary (lower graphs) parameters. The dose intervals are divided (binned) in 3 equal parts, the points are plotted at the average dose value of each bin and represent the ratio of patients with and without symptoms. The error bars are the $68 \%$ confidence intervals (Chi-square) and depend on the number of patients in the bin. The black dots are the individual patients without symptoms; red dots are patients with symptoms. The logistic regression uses all data at once, so the binning does not influence the significance and was done only for display purposes
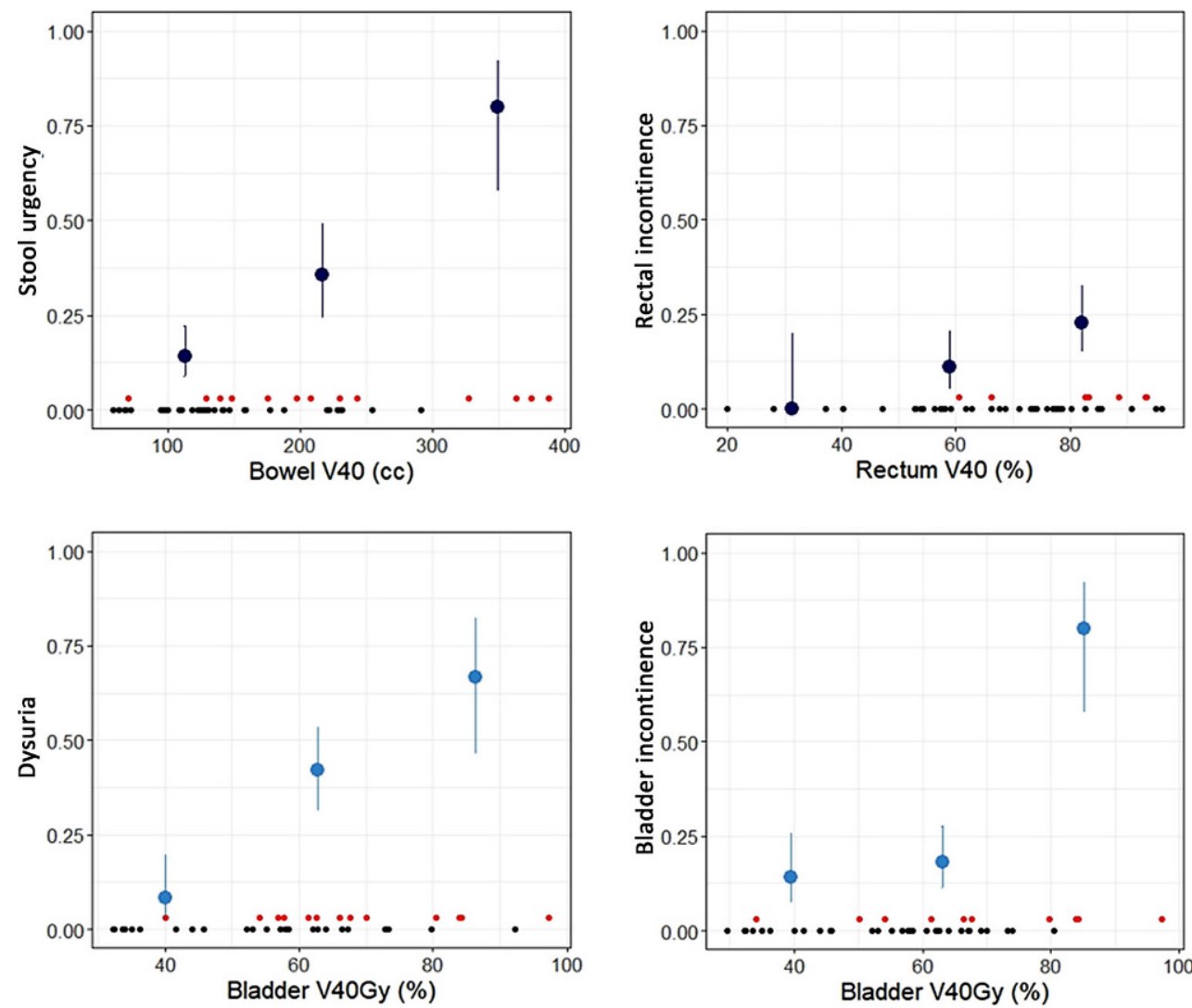

CHT, smoking and age and in case of bladder incontinence, also by alcohol use (Table 2). Despite the low incidence of bladder incontinence, a clear Bladder $\mathrm{V}_{40 \mathrm{~Gy}}$ dependency (consistent between questionnaires) was observed. For bladder incontinence, the $\mathrm{TD}_{50}$ of $\mathrm{V}_{40 \mathrm{~Gy}}$ was obtained for an irradiated volume of $80-90 \%$.

\section{Acute general side effects}

Just before the start of BT, there was a significant correlation between weight loss and the EBRT body V43Gy (Table 2). After the first BT fraction, weight loss increased rapidly with $4 \mathrm{~kg}$ on average, due to limited oral intake during BT (which implies over $48 \mathrm{~h}$ parenteral nutrition) and the correlation of weight loss and EBRT dose became less prominent. Lumbar pain recovered during treatment compared to baseline, with the lowest incidence in week 4; afterwards it increased after epidural anesthesia and bed rest during the days of BT. The recovery of lumbar pain in the follow-up should be evaluated with caution, as some confounding factors need be taken into account such as lymphadenectomy, epidural anesthesia, bed rest during the days of BT.

\section{Discussion}

The EBRT treatment techniques in cervix cancer radiotherapy have evolved during the decades. Several studies compared 2D, 3D and IMRT technique, providing the same local control and overall survival with significantly reduced gastrointestinal and genitourinary toxicity in IMRT treatment group [35-37].

The current pilot study was designed as a prospective observational and hypothesis generating one, with the main objective to explore correlations between acute toxicity and DVH parameters in this context. These correlations can later be used to reduce early effects as much as possible and to avoid consequential late side effects, since some acute symptoms can persist over a longer period of time and become chronic. Despite the limited number of patients and low frequency of reported acute side effects, it was possible to isolate dose-effects in GU and GI toxicity and some patient specific factors. Within this cohort there were different types of treatment planning, i.e., 3D-CRT, single plan VMAT and ART. This heterogeneity in treatment fields and nodal dose delivered, provided a larger range of dose parameters than a study of each single technique would have done.

The evolution of EBRT treatment techniques in our center over time is clearly reflected in clinical results of 
this study. As the variables "treatment technique" and "irradiated volume" are correlated and the subgroups were small, the clinical results obtained did not reveal a difference in toxicity between VMAT-ART and VMAT. On the other hand, there was a selection bias since VMATART was intentionally limited to patients classified as "movers" with a more complicated and changing anatomy. Another contributing factor was target definition, mainly in terms of concepts (EMBRACE-II protocol). A similar trend in treated volumes was observed recently in the evolution of EMBRACE-I/-II study when evaluating treatment technique, treatment protocol and para-aortic irradiation [38].

Despite all technological advancements, accurate assessment of the actually delivered doses remains challenging. Because of daily differences in OARs volumes, DVHs of treatment plans are not representative for the whole treatment. Therefore, the analysis of the $\mathrm{V}_{43 \mathrm{~Gy}}$ is probably a better means to assess treatment plans for EBRT of cervix cancer, as OARs move to different dose regions. In the current study $\mathrm{V}_{43 \mathrm{~Gy}}$ correlated linearly with weight loss during the treatment.

EBRT of cervix cancer with its rather challenging target volume, surrounded by critical OARs that have a direct impact on QoL, is one of the main clinical sites where ART is explored. However, there is only a limited number of studies regarding prospective assessment of physician and patient reported outcome of acute morbidity in this context $[14,39]$. Although toxicity was evaluated with standardized questionnaires, a considerable discordance was found for patient reported vs physician reported outcome, mainly in dysuria evaluation. This should be taken into account because side effects evaluated by physicians as low grade, could have an important impact on QoL [40].

When assessing patient reported outcomes, it is of utmost importance to perform a baseline assessment as many patients report GI, GU or general symptoms before treatment (Appendix, Table B.1; [8]). The incidence of GI symptoms was already two times higher in the second week of treatment, which can be explained as a direct effect of small intestines exposure, changes in irrigation, epithelial atrophy and chemotherapy [41-43], and not just by the irradiated volume. The incidence peak was in week 5-6 for the majority of the symptoms; however almost complete recovery was present at the 3 month follow-up. These findings concur with data published by Heijkoop et al. [14].

From the general symptoms, lumbar pain seems to have a dose effect in multivariate analysis, but some confounding factors need to be taken into account. For example, if patients report lumbar pain at the baseline, it could be a result of lymphadenectomy or the tumor itself.

The BT as confounding factor in DVH evaluation of all GI, GU and general symptoms was not taken into account.
Most of significant parameters were found at timepoints before BT. For the parameters assessed at a later timepoint (i.e., Bladder incontinence at the 6-week follow-up) the EBRT dose effect was highly significant even without considering BT dose.

The influence of the chemotherapy regime is difficult to assess as almost all patients got cisplatin in this study. Both the PsP parameter CHT or the number of completed chemotherapy cycles seem to influence the severity of side effects a little, but did not remain significant in the multivariate analysis (except for rectal incontinence). Prior studies reported on acute side effects with and without chemotherapy. Morbidity was described as elevated [44] or similar [45] in the combination treatment.

For patients undergoing cervix cancer treatments involving radiation therapy, numerous other studies related to QLQ evaluation were published [8, 18, 20-22]. The most reported GU symptoms were urinary frequency, cystitis and incontinence [9]; the most reported GI symptoms were diarrhea, stool urgency and rectal incontinence [10]. The majority of patients treated in those studies received 3D-CRT, i.e. $74 \%$ in [8], 63\% in [10] and [9]. In an IMRT study comprising 50 patients treated with 45-50 Gy diarrhea was the most common symptom and the cut-off point for small bowel $\geq \mathrm{G} 2$ toxicity was $\mathrm{V}_{45 \mathrm{~Gy}}>150 \mathrm{~cm}^{3}$ (65\% vs. $33 \%$ in $\mathrm{V}_{45 \mathrm{~Gy}}<150 \mathrm{~cm}^{3}$ ) [46]. Although toxicity was evaluated by RTOG scale, the results concur with QUANTEC constraints $\mathrm{V}_{45 \mathrm{~Gy}}<195 \mathrm{~cm}^{3}$ [47].

In our cohort, where 94\% received VMAT and 31\% VMAT-ART, low grade diarrhea, stool urgency, rectal incontinence, bleeding from GI and dysuria and bladder incontinence from GU symptoms were the most common toxicities. Only stool urgency, rectal and bladder incontinence and weight loss showed a significantly increasing distribution of incidences over the entire dose range (Fig. 3) Furthermore, a correlation between dysuria with Bladder $\mathrm{V}_{40 \mathrm{~Gy}}$, stool urgency and incontinence with Bowel and Rectum $\mathrm{V}_{40 \mathrm{G} y}$ was observed. Based on these data, the following treatment planning objectives are recommended to minimize stool urgency, rectal and urinary incontinence: bowel $\mathrm{V}_{40 \mathrm{~Gy}} \leq 250 \mathrm{~cm}^{3}$, rectum $\mathrm{V}_{40 \mathrm{~Gy}} \leq 80 \%$ and bladder $\mathrm{V}_{40 \mathrm{~Gy}} \leq 80-90 \%$, respectively. These results concur reasonably with planning aims in EMBRACE-II [29], which were derived from a cohort of representative dose distributions.

With ART, less body volume was irradiated to mid and low dose volume levels than with the corresponding robust plan. It can be speculated that this could contribute to morbidity reduction. However, para-aortic extended fields may have a larger impact on normal tissue exposure than the additional organ sparing through ART. Therefore, a future comparison of adaptive and nonadaptive techniques should include a correction for extended field irradiation. 
The ongoing EMBRACE-II study aims to further reduce morbidity by reducing the irradiated volume through reduced PTV margins and IMRT/VMAT following dose volume constraints for OARs. The EMBRACE-II study with a considerable patient cohort can certainly contribute to answer this clinical and scientific question and provide correlations with late morbidity, including a novel approach to distinguish between late transient and long-lasting side effects [48].

\section{Conclusion}

This prospective study demonstrated the impact of treatment technique on quality of life (QoL) of cervix cancer patients undergoing radiochemotherapy. In general, a peak of impaired QoL was observed in treatment weeks 5-6, although this was transient with a recovery at the 3-month follow-up. The following external beam radiotherapy (EBRT) planning objectives may be used to reduce early morbidity: bowel $\mathrm{V}_{40 \mathrm{~Gy}}<250 \mathrm{~cm}^{3}$ for stool urgency, rectum $\mathrm{V}_{40 \mathrm{~Gy}}<80 \%$ for rectal incontinence and bladder $\mathrm{V}_{40 \mathrm{~Gy}}<80-90 \%$ for urinary incontinence.

Open Access This article is licensed under a Creative Commons Attribution 4.0 International License, which permits use, sharing, adaptation, distribution and reproduction in any medium or format, as long as you give appropriate credit to the original author(s) and the source, provide a link to the Creative Commons licence, and indicate if changes were made. The images or other third party material in this article are included in the article's Creative Commons licence, unless indicated otherwise in a credit line to the material. If material is not included in the article's Creative Commons licence and your intended use is not permitted by statutory regulation or exceeds the permitted use, you will need to obtain permission directly from the copyright holder. To view a copy of this licence, visit http://creativecommons.org/licenses/by/4. $0 /$.

\section{Appendix A}

\section{Collected and evaluated side effects}

GI: stool consistency, diarrhea, constipation, bloating, flatulence, stool urgency, rectal tenesmus, rectal mucus, rectal hemorrhage, rectal Incontinence, proctitis.

GU: micturition during the day, nocturia, urinary urgency, bladder tenesmus, bladder bleeding, dysuria, bladder incontinence and cystitis.

General side effects: weight loss, fatigue, insomnia, limb edema, tinnitus, paresthesia, back pain, pelvic pain.

\section{Dynamics of those side effects that were analyzed and were associated with a dose-effect}


Fig. A.1 Dynamics of side effects
CTCAE grade / Bristol stool form
QLQ
$\square 0$
$\square$ None
1/4-5 Normal
2/6 Mushy
A little
3/ 7 Liquid
Quite a bit

a

Stool urgency - CTCAE

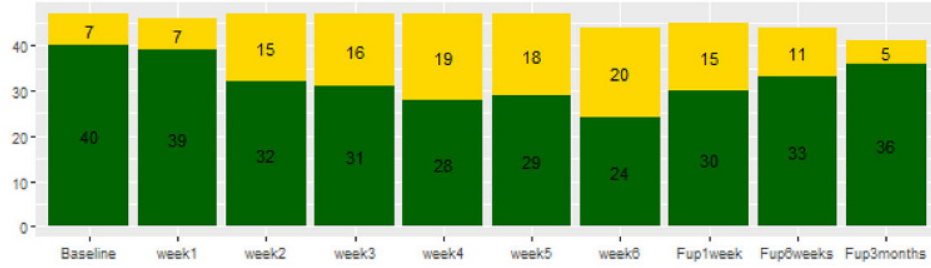

Stool urgency - Patient reported outcome - QLQ56

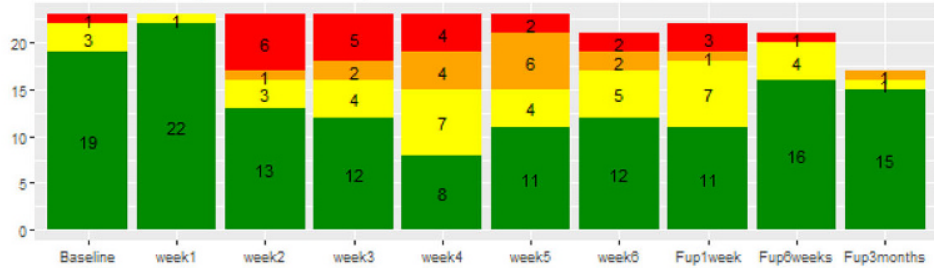

b

Rectal incontinence - CTCAE

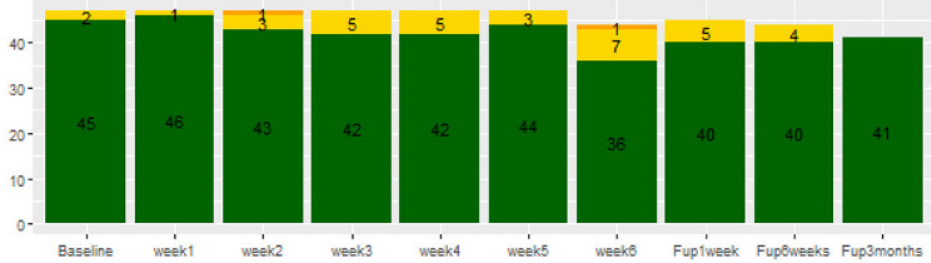

Rectal incontinence - Patient reported outcome - QLQ32

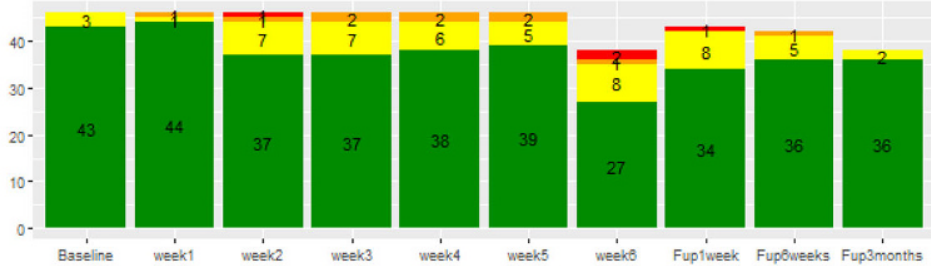

C

Stool urgency - CTCAE

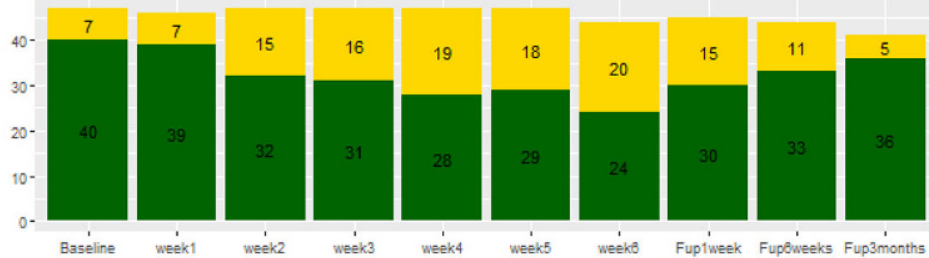

Stool urgency - Patient reported outcome - QLQ56

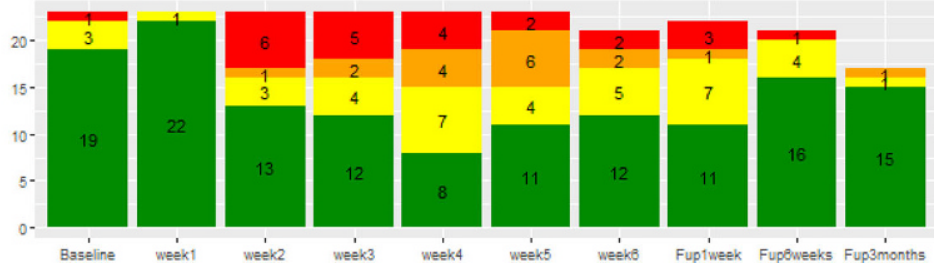

week5

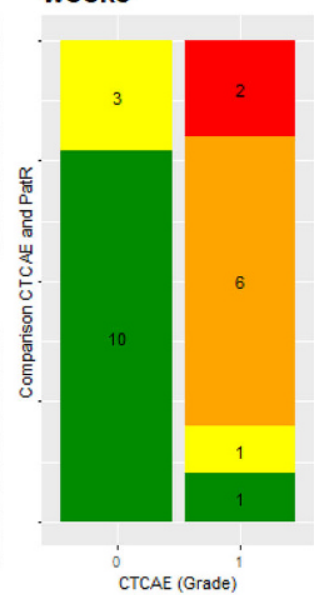

\section{week6}

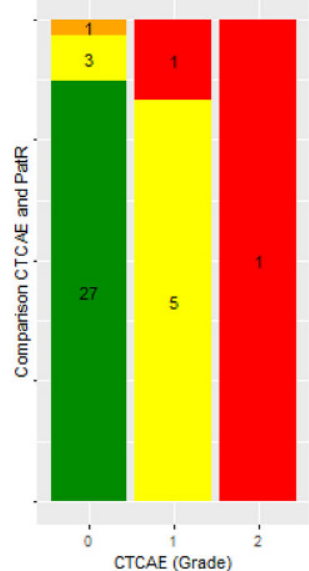

week5

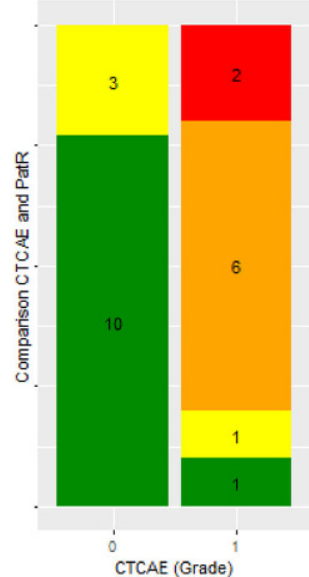


Fig. A.1 (Continued)

d

Rectal hemorrhage - CTCAE

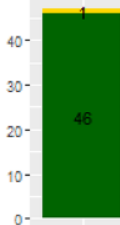

Baseline weekt

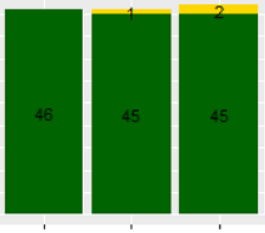

week2

week 3

week5
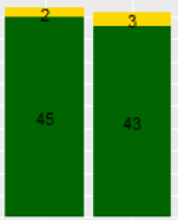

(1)

Rectal hemorrhage - Patient reported outcome - QLQ33
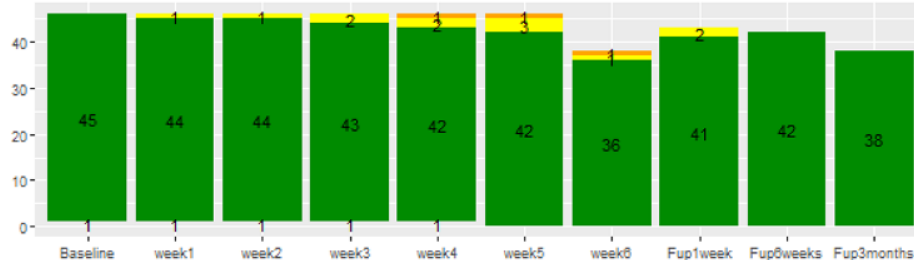

weeks Fupiweek Fupoweeks Fup3mionths

e

Stool urgency - Bristol scale

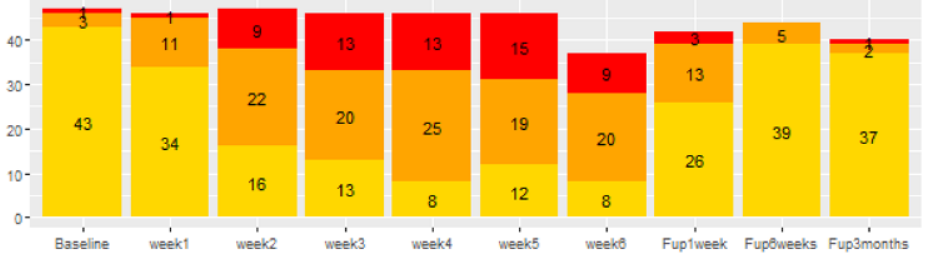

f

\section{Dysuria - CTCAE}

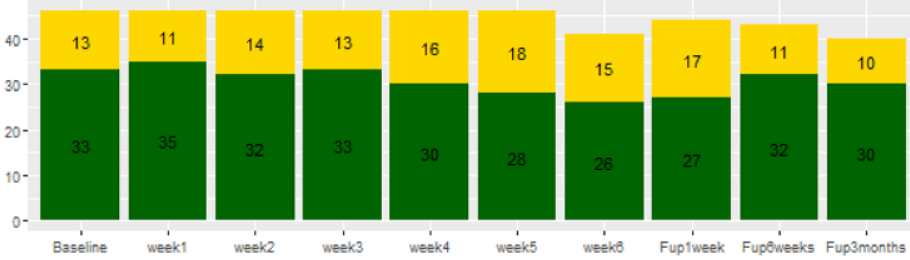

Bsseline week1 week2 week3 week4 week5 we
Dysuria - Patient reported outcome - QLQ35
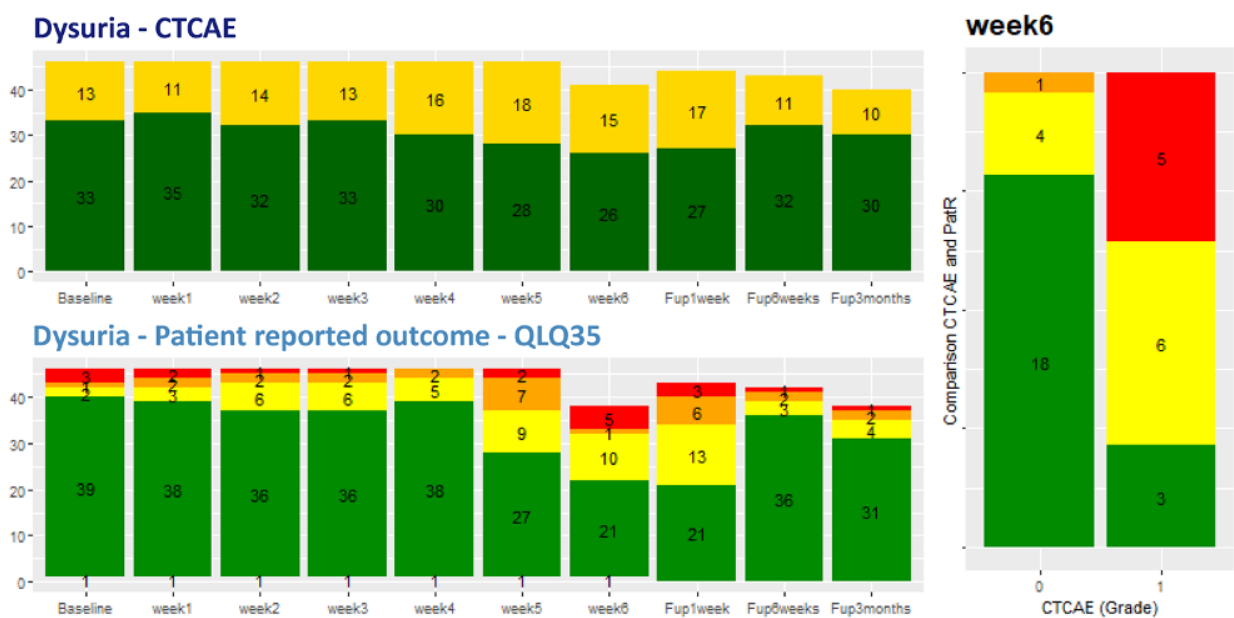

In the right comparison plot, we see that 8 patients disagreed with their physicians regarding dysuria. 
Fig. A.1 (Continued)

\section{g}

Bladder incontinence - CTCAE

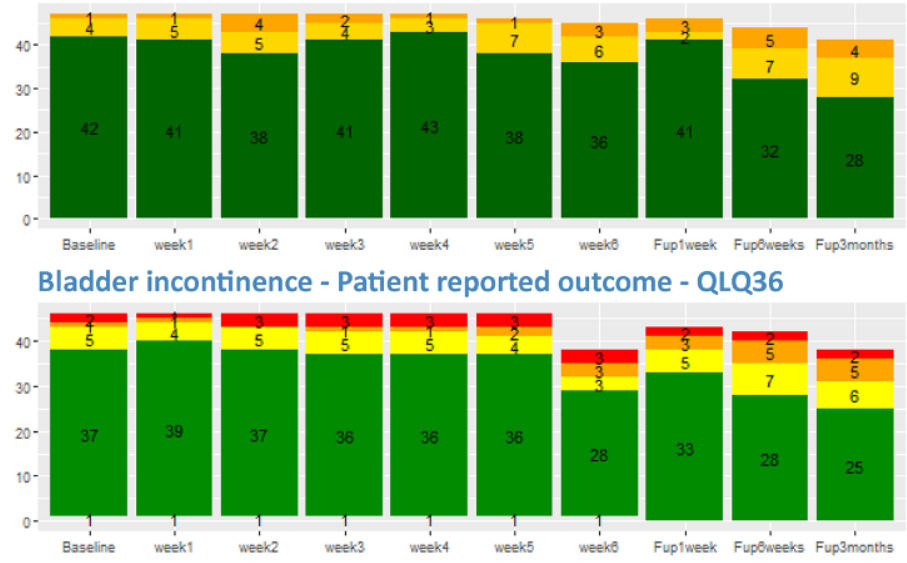

Followup6weeksafte

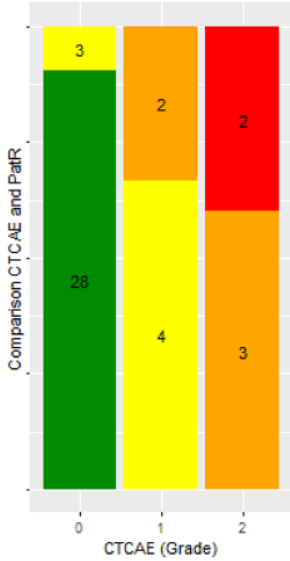

h

Back pain - CTCAE

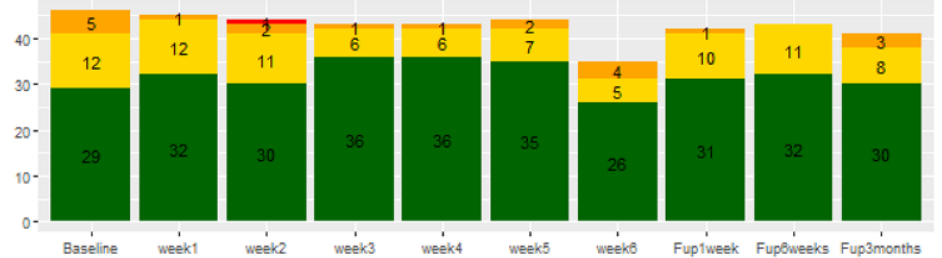

Back pain - Patient reported outcome - QLQ9
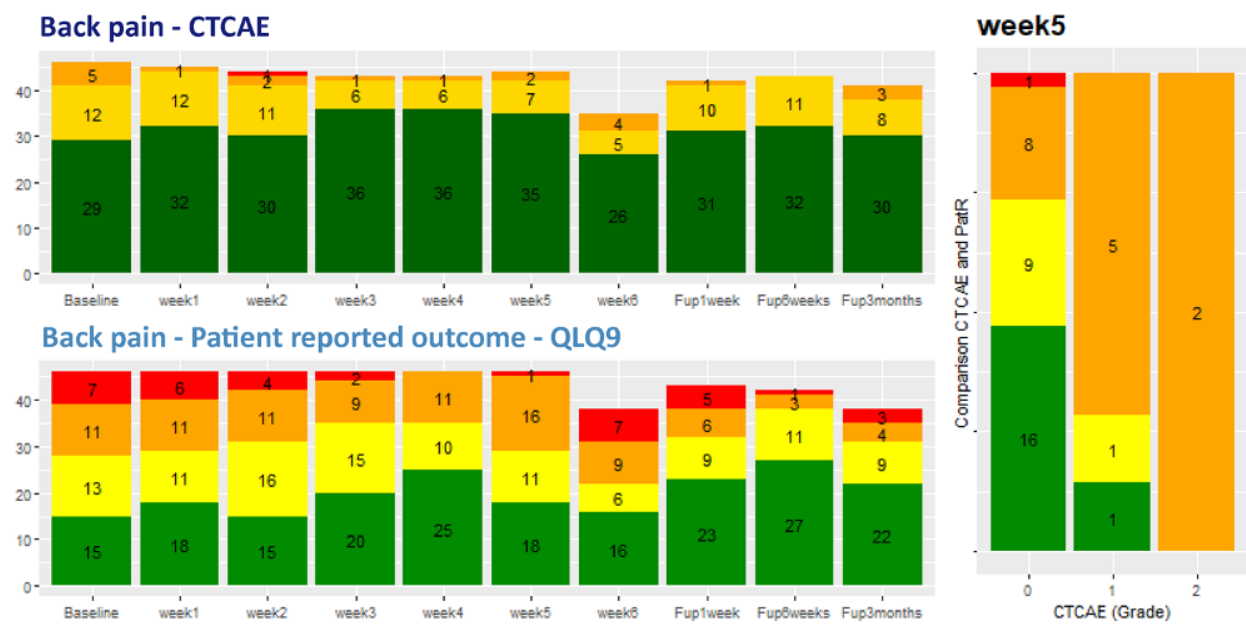


\section{Appendix B}

Table B.1 Side effects (>grade 1) present before start of treatment

\begin{tabular}{|c|c|c|}
\hline None or few & $\begin{array}{l}10-50 \% \text { of the pa- } \\
\text { tients }\end{array}$ & $\begin{array}{l}>50 \% \text { of the pa- } \\
\text { tients }\end{array}$ \\
\hline Edema limbs & Pelvic pain & Fatigue \\
\hline Tinnitus & Constipation & Insomnia \\
\hline Paresthesia & Micturition daytime & Back pain \\
\hline Nausea & $\begin{array}{l}\text { Micturition night- } \\
\text { time }\end{array}$ & Flatulence \\
\hline Vomiting & Dysuria & Vaginal discharge \\
\hline Stool consistency & $\begin{array}{l}\text { Bladder inconti- } \\
\text { nence }\end{array}$ & \\
\hline Diarrhea & Vaginal pain & \\
\hline Stool urgency & Vaginal hemorrhage & \\
\hline Rectal tenesmus & $\begin{array}{l}\text { Vaginal inflamma- } \\
\text { tion }\end{array}$ & \\
\hline Rectal mucus & Bloating & \\
\hline Rectal hemorrhage & & \\
\hline Rectal incontinence & & \\
\hline Proctitis & & \\
\hline Urinary urgency & & \\
\hline $\begin{array}{l}\text { Bladder spasm/ } \\
\text { tenesmus }\end{array}$ & & \\
\hline Bladder hemorrhage & & \\
\hline Cystitis & & \\
\hline Vaginal mucositis & & \\
\hline
\end{tabular}

Acknowledgements The financial support by the (Austrian) Federal Ministry for Digital and Economic Affairs and the National Foundation for Research, Technology and Development is gratefully acknowledged.

Funding The financial support by the (Austrian) Federal Ministry for Digital and Economic Affairs and the National Foundation for Research, Technology and Development is gratefully acknowledged.

Funding Open access funding provided by Medical University of Vienna.

\section{Declarations}

Conflict of interest Y. Seppenwoolde, K. Majercakova, M. Buschmann, E. Dörr, A.E. Sturdza, M.P. Schmid, R. Pötter and D. Georg declare that they have no competing interests.

Ethical standards The trial was registered at ethics committee of the Medical University of Vienna under the EK-Nr: 2009/2014. All individuals gave consent to participate.

\section{References}

1. Cibula D, Pötter R, Planchamp F, Avall-Lundqvist E, Fischerova D, Haie Meder C et al (2018) The European society of gynaecological oncology/European society for radiotherapy and oncology/ European society of pathology guidelines for the management of patients with cervical cancer. Radiother Oncol 127:404-416. https://doi.org/10.1016/j.radonc.2018.03.003

2. Du XL, Tao J, Sheng XG, Lu CH, Yu H, Wang C et al (2012) Intensity-modulated radiation therapy for advanced cervical cancer: a comparison of dosimetric and clinical outcomes with conventional radiotherapy. Gynecol Oncol 125:151-157. https://doi.org/10.1016/ j.ygyno.2011.12.432

3. Gandhi AK, Sharma DN, Rath GK, Julka PK, Subramani V, Sharma S et al (2013) Early clinical outcomes and toxicity of intensity modulated versus conventional pelvic radiation therapy for locally advanced cervix carcinoma: a prospective randomized study. Int J Radiat Oncol Biol Phys 87:542-548. https://doi.org/10. 1016/j.ijrobp.2013.06.2059

4. van de Bunt L, Jürgenliemk-Schulz IM, de Kort GA, Roesink JM, Tersteeg RJ, van der Heide UA (2008) Motion and deformation of the target volumes during IMRT for cervical cancer: what margins do we need? Radiother Oncol 88:233-240. https://doi.org/10.1016/ j.radonc.2007.12.017

5. Taylor A, Powell ME (2008) An assessment of interfractional uterine and cervical motion: implications for radiotherapy target volume definition in gynaecological cancer. Radiother Oncol 88:250-257. https://doi.org/10.1016/j.radonc.2008.04.016

6. Beadle BM, Jhingran A, Salehpour M, Sam M, Iyer RB, Eifel PJ (2009) Cervix regression and motion during the course of external beam chemoradiation for cervical cancer. Int J Radiat Oncol Biol Phys 73:235-241. https://doi.org/10.1016/j.ijrobp.2008.03.064

7. Chan P, Dinniwell R, Haider MA, Cho YB, Jaffray D, Lockwood G et al (2008) Inter- and intrafractional tumor and organ movement in patients with cervical cancer undergoing radiotherapy: a cinematic-MRI point-of-interest study. Int J Radiat Oncol Biol Phys 70:1507-1515. https://doi.org/10.1016/j.ijrobp.2007.08.055

8. Kirchheiner K, Pötter R, Tanderup K, Lindegaard JC, HaieMeder C, Petrič P et al (2016) Health-related quality of life in locally advanced cervical cancer patients after definitive chemoradiation therapy including image guided adaptive brachytherapy: an 
analysis from the EMBRACE study. Int J Radiat Oncol Biol Phys 94:1088-1098. https://doi.org/10.1016/j.ijrobp.2015.12.363

9. Jensen NBK, Pötter R, Kirchheiner K, Fokdal L, Lindegaard JC, Kirisits C et al (2018) Bowel morbidity following radiochemotherapy and image-guided adaptive brachytherapy for cervical cancer: physician- and patient reported outcome from the EMBRACE study. Radiother Oncol 127:431-439. https://doi.org/10.1016/j. radonc.2018.05.016

10. Fokdal L, Pötter R, Kirchheiner K, Lindegaard JC, Jensen NBK, Kirisits $C$ et al (2018) Physician assessed and patient reported urinary morbidity after radio-chemotherapy and image guided adaptive brachytherapy for locally advanced cervical cancer. Radiother Oncol 127:423-430. https://doi.org/10.1016/j.radonc.2018.05.002

11. Ahmad R, Hoogeman MS, Bondar M, Dhawtal V, Quint S, De Pree I et al (2011) Increasing treatment accuracy for cervical cancer patients using correlations between bladder-filling change and cervix-uterus displacements: proof of principle. Radiother Oncol 98:340-346. https://doi.org/10.1016/j.radonc.2010.11.010

12. Bondar L, Hoogeman M, Mens JW, Dhawtal G, de Pree I, Ahmad R et al (2011) Toward an individualized target motion management for IMRT of cervical cancer based on model-predicted cervixuterus shape and position. Radiother Oncol 99:240-245. https://doi. org/10.1016/j.radonc.2011.03.013

13. Heijkoop ST, Langerak TR, Quint S, Bondar L, Mens JW, Heijmen BJ et al (2014) Clinical implementation of an online adaptive plan-of-the-day protocol for nonrigid motion management in locally advanced cervical cancer IMRT. Int J Radiat Oncol Biol Phys 90:673-679. https://doi.org/10.1016/j.ijrobp.2014.06.046

14. Heijkoop ST, Nout RA, Quint S, Mens JWM, Heijmen BJM, Hoogeman MS (2017) Dynamics of patient reported quality of life and symptoms in the acute phase of online adaptive external beam radiation therapy for locally advanced cervical cancer. Gynecol Oncol 147:439-449. https://doi.org/10.1016/j.ygyno.2017.08.009

15. Buschmann M, Majercakova K, Sturdza A, Smet S, Najjari D, Daniel $M$ et al (2018) Image guided adaptive external beam radiation therapy for cervix cancer: evaluation of a clinically implemented plan-of-the-day technique. Z Med Phys 28:184-195. https://doi.org/10.1016/j.zemedi.2017.09.004

16. Dörr W, Hendry JH (2001) Consequential late effects in normal tissues. Radiother Oncol 61:223-231. https://doi.org/10.1016/S01678140(01)00429-7

17. Wang CJ, Leung SW, Chen HC, Sun LM, Fang FM, Huang E et al (1998) The correlation of acute toxicity and late rectal injury in radiotherapy for cervical carcinoma: evidence suggestive of consequential late effect (CQLE). Int J Radiat Oncol Biol Phys 40:85-91. https://doi.org/10.1016/S0360-3016(97)00560-9

18. Park SY, Bae DS, Nam JH, Park CT, Cho CH, Lee JM et al (2007) Quality of life and sexual problems in disease-free survivors of cervical cancer compared with the general population. Cancer 110:2716-2725. https://doi.org/10.1002/cncr.23094

19. JKirwan JM, Symonds P, Green JA, Tierney J, Collingwood M, Williams CJ (2003) A systematic review of acute and late toxicity of concomitant chemoradiation for cervical cancer. Radiother Oncol 68:217-226. https://doi.org/10.1016/S0167-8140(03)00197-X

20. Bjelic-Radisic V, Jensen PT, Vlasic KK, Waldenstrom AC, Singer S, Chie W (2012) Quality of life characteristics inpatients with cervical cancer. Eur J Cancer 48:3009-3018. https://doi.org/10.1016/j. ejca.2012.05.011

21. Ferrandina G, Mantegna G, Petrillo M, Fuoco G, Venditti L, Terzano S (2012) Quality of life and emotional distress in early stage and locally advanced cervical cancer patients: a prospective, longitudinal study. Gynecol Oncol 124:389-394. https://doi.org/ 10.1016/j.ygyno.2011.09.041

22. Korfage IJ, Essink-Bot ML, Mols F, van de Poll-Franse L, Kruitwagen R, van Ballegooijen M (2009) Health-related quality of life in cervical cancer survivors: a population-based survey. Int J Radiat
Oncol Biol Phys 73:1501-1509. https://doi.org/10.1016/j.ijrobp. 2008.06.1905

23. Bentzen SM, Constine LS, Deasy JO, Eisbruch A, Jackson A, Marks LB et al (2010) Quantitative analyses of normal tissue effects in the clinic (QUANTEC): an introduction to the scientific issues. Int J Radiat Oncol Biol Phys 76:S3-9. https://doi.org/10. 1016/j.ijrobp.2009.09.040

24. Xu B, Guo Y, Chen Y, Lu H, Tang T, Yue $\mathrm{Z}$ et al (2015) Is the irradiated small bowel volume still a predictor for acute lower gastrointestinal toxicity during preoperative concurrent chemoradiotherapy for rectal cancer when using intensity-modulated radiation therapy? Radiat Oncol 10:257. https://doi.org/10.1186/ s13014-015-0566-6

25. Lee TF, Huang EY (2014) The different dose-volume effects of normal tissue complication probability using lasso for acute smallbowel toxicity during radiotherapy in gynecological patients with or without prior abdominal surgery. Biomed Res Int 2014:143020. https://doi.org/10.1155/2014/143020

26. Viswanathan AN, Yorke ED, Marks LB, Eifel PJ, Shipley WU (2010) Radiation dose-volume effects of the urinary bladder. Int J Radiat Oncol Biol Phys 76:S116-22. https://doi.org/10.1016/j. ijrobp.2009.02.090

27. Thor M, Olsson C, Oh JH, Petersen SE, Alsadius D, Bentzen L (2016) Urinary bladder dose-response relationships for patientreported genitourinary morbidity domains following prostate cancer radiotherapy. Radiother Oncol 119:117-122. https://doi.org/10. 1016/j.radonc.2016.01.013

28. Serrano NA, Kalman NS, Anscher MS (2017) Reducing rectal injury in men receiving prostate cancer radiation therapy: current perspectives. Cancer Manag Res 9:339-350. https://doi.org/10.2147/ CMAR.S118781

29. EMBRACE (2020) EMBRACE studies and EMBRACE research. https://www.embracestudy.dk/. Accessed 17 May 2020

30. National Cancer Institute (2010) Common terminology criteria for adverse events (CTCAE) (Version 4.0)

31. Lewis SJ, Heaton KW (1997) Stool form scale as a useful guide to intestinal transit time. Scand J Gastroenterol 32:920-924. https:// doi.org/10.3109/00365529709011203

32. R core team (2017) R: A language and environment for statistical computing. R Foundation of Statistical Computing, Vienna, Austria

33. Friedman AJ, Hastie T, Simon N, Tibshirani R, Hastie MT (2020) Lasso and elastic-net regularized generalized linear models. https:// cran.r-project.org/web/packages/glmnet/glmnet.pdf. Accessed 17 May 2020

34. Friedman J, Hastie T, Tibshirani R (2010) Regularization paths for generalized linear models via coordinate descent. J Stat Softw 33:1-22. https://doi.org/10.18637/jss.v033.i01

35. Gandhi AK, Sharma DN, Rath GK, Julka PK, Subramani V, Sharma S, Manigandan D, Laviraj MA, Kumar S, Thulkar S (2013) Early clinical outcomes and toxicity of intensity modulated versus conventional pelvic radiation therapy for locally advanced cervix carcinoma: a prospective randomized study. Int J Radiat Oncol Biol Phys 87:542-548. https://doi.org/10.1016/j.ijrobp.2013.06.2059

36. Naik A, Gurjar OP, Gupta KL, Singh K, Nag P, Bhandari V (2016) Comparison of dosimetric parameters and acute toxicity of intensity-modulated and threedimensional radiotherapy in patients with cervix carcinoma: a randomized prospective study. Cancer Radiother 20:370-376. https://doi.org/10.1016/j.canrad.2016.05.011

37. Lin Y, Chen K, Lu Z, Zhao L, Tao Y, Ouyang Y, Cao X (2018) Intensity-modulated radiation therapy for definitive treatment of cervical cancer: a meta-analysis. Radiat Oncol 13:177. https://doi.org/ 10.1186/s13014-018-1126-7

38. Berger T, Seppenwoolde Y, Pötter R, Assenholt MS, Lindegaard JC, Nout RA et al (2019) Importance of technique, target selection, contouring, dose prescription, and dose-planning in external beam radiation therapy for cervical cancer: evolution of practice from 
EMBRACE-I to II. Int J Radiat Oncol Biol Phys 104:885-894. https://doi.org/10.1016/j.ijrobp.2019.03.020

39. Reijtenbagh DMW, Godart J, Mens JWM, Heijkoop ST, Heemsbergen WD, Hoogeman MS (2020) Patient-reported acute GI symptoms in locally advanced cervical cancer patients correlate with rectal dose. Radiother Oncol 148:38-43. https://doi.org/10.1016/j. radonc.2020.03.035

40. Kirchheiner K, Nout R, Lindegaard J, Petrič P, Limbergen EV, Jürgenliemk-Schulz IM et al (2012) Do clinicians and patients agree regarding symptoms? A comparison after definitive radiochemotherapy in 223 uterine cervical cancer patients. Strahlenther Onkol 188:933-939. https://doi.org/10.1007/s00066-0120156-6

41. Tanderup K, Georg D, Pötter R, Kirisits C, Grau C, Lindegaard JC (2010) Adaptive management of cervical cancer radiotherapy. Semin Radiat Oncol 20:121-129. https://doi.org/10. 1016/j.semradonc.2009.11.006

42. Shadad AK, Sullivan FJ, Martin JD, Egan LJ (2013) Gastrointestinal radiation injury: symptoms, risk factors and mechanisms. World J Gastroenterol 19:185-198. https://doi.org/10.3748/wjg. v19.i2.185

43. Andreyev J (2005) Gastrointestinal complications of pelvic radiotherapy: are they of any importance? Gut 54:1051-1054. https:// doi.org/10.1136/gut.2004.062596

44. Morris M, Eifel PJ, Lu J, Grigsby PW, Levenback C, Stevens RE et al (1999) Pelvic radiation with concurrent chemotherapy com- pared with pelvic and para-aortic radiation for high-risk cervical cancer. N Engl J Med 340:1137-1143. https://doi.org/10.1056/ NEJM199904153401501

45. Saad A, Lo SS, Han I, Keole S, Lee CP, Tekyi-Mensah S et al (2004) Radiation therapy with or without chemotherapy for cervical cancer with periaortic lymph node metastasis. Am J Clin Oncol 27:256-263. https://doi.org/10.1097/01.coc.0000092564.16409.cd

46. Simpson DR, Song WY, Moiseenko V, Rose BS, Yashar CM, Mundt AJ et al (2012) Normal tissue complication probability analysis of acute gastrointestinal toxicity in cervical cancer patients undergoing intensity modulated radiation therapy and concurrent cisplatin. Int J Radiat Oncol Biol Phys 83:e81-6. https://doi.org/10. 1016/j.ijrobp.2011.12.012

47. Kavanagh BD, Pan CC, Dawson LA, Das SK, Li XA, Ten Haken RK et al (2010) Radiation dose-volume effects in the stomach and small bowel. Int J Radiat Oncol Biol Phys 76:S101-7. https://doi.org/10.1016/j.ijrobp.2009.05.071

48. Kirchheiner K, Pötter R, Nout RA, Schwartz-Vittrup A, Holzner B, Bentzen SM et al (2020) Late, persistent, substantial, treatment-related symptoms after radiation therapy (LAPERS): a new method for longitudinal analysis of late morbidity-applied in the EMBRACE study. Int J Radiat Oncol Biol Phys 106:300-309. https://doi.org/10.1016/j.ijrobp.2019.10.027 